\title{
NEW VARIANCE RATIO TESTS TO IDENTIFY RANDOM WALK FROM THE GENERAL MEAN REVERSION MODEL
}

\author{
KIN LAM, MAY CHUN MEI WONG, AND WING-KEUNG WONG
}

Received 13 June 2005; Revised 30 November 2005; Accepted 9 December 2005

We develop some properties on the autocorrelation of the $k$-period returns for the general mean reversion (GMR) process in which the stationary component is not restricted to the $\mathrm{AR}(1)$ process but takes the form of a general ARMA process. We then derive some properties of the GMR process and three new nonparametric tests comparing the relative variability of returns over different horizons to validate the GMR process as an alternative to random walk. We further examine the asymptotic properties of these tests which can then be applied to identify random walk models from the GMR processes.

Copyright (C) 2006 Kin Lam et al. This is an open access article distributed under the Creative Commons Attribution License, which permits unrestricted use, distribution, and reproduction in any medium, provided the original work is properly cited.

\section{Introduction}

The efficiency of the securities markets constitutes the basis for most research conducted by financial economists on the impact of the random walk model on stock prices or other financial data. Some accept the random walk hypothesis but some reject it. Random walks, a special case of unit root processes, help identify the kinds of shocks that drive stock prices to make independent successive price changes. If a stock price series follows a random walk, the price has no mean reversion tendency and, hence, a shock to the price will lead to increasing deviations from its long-run equilibrium. If, on the other hand, a stock price series does not follow a random walk but manifests significant stationary components, it follows that future equity prices are predictable based on past prices. Thus, it is possible to design profitable trading schemes based on historical equity data.

Early statistics to test the random walk processes usually emphasize the examination of serial correlation. A commonly used statistic to test the random walk hypothesis is the unit root tests developed by Dickey and Fuller [17, 18]. The shortcoming of using this test is that it is a necessary but not a sufficient condition to show that random 
walk is a unit root process as a random walk for stock prices means that returns must be uncorrelated but the unit root test allows predictable elements (Lo and MacKinlay [39]).

As the variance ratio tests developed by Lo and MacKinlay [39] have been found to be more powerful than unit root tests, they are more often used by both academics and practitioners to test the null hypothesis of random walk processes for stock prices, a reflection of market efficiency upon acceptance of the hypothesis. In testing the random walk hypothesis, some simply test random walk against non-random walk. However, the random walk model could be too simple while the non-random walk model could be too general, thus it would not reflect the complexity of stock return behavior which could consist of components of both random walk and non-random walk models. To improve the validity and reliability of the test in more complicated situations, some restrictions apply to alternative models set in the alternative hypothesis. One category of the alternatives (Summers [49]) is the mean reversion model (fads) ("fad" means there is a tendency towards herding in the market) which is the sum of a random walk and an AR(1) stationary mean-reverting process with a mean reversion component resulting from temporary divergences of prices from fundamental value.

The mean reversion could be explained by the overreaction hypothesis defined by De Bondt and Thaler [15] who suggest that extreme movements in stock prices are followed by movements in the opposite direction to "correct" the initial overreaction and that the greater the magnitude of initial price change, the more extreme the offsetting reaction. The idea of fads in investor attitudes may influence stock prices such that the prices have a tendency to gravitate back to fundamentals in the long run. Some suggest that stock prices will be mean-reverting over long horizons. In addition, from the long-term perspective, many studies find that stock returns display a significant negative serial correlation. As a simple fads model may not be able to capture the mean-reverting process over long horizons nor capture the behavior of being negative serial correlated over long horizons, a general mean reversion (GMR) model is then required to extend the fads model in which the temporary component follows a general ARMA stationary process. The test of random walk against GMR becomes important and we will study this hypothesis in this paper.

In this paper, we study the GMR process in which the stationary component is not restricted to the $\mathrm{AR}(1)$ process but takes the form of a general ARMA process. We first derive several properties about the first-order autocorrelations of the $k$-period returns and the variance ratios of the mean reversion process, and thereafter develop some properties of the GMR process. Based on these properties, we further develop three new nonparametric tests comparing the relative variability of returns over different horizons to test the GMR model as an alternative to random walk. We further examine the asymptotic properties of these tests which can then be applied to identify random walk models from the GMR processes.

This paper is organized as follows. We begin with a series of literature review in Section 2. We discuss the theories of both random walk and the GMR process and study some properties of the general GMR process in Section 3. In Section 4, we develop three new nonparametric tests for random walk null versus the GMR alternative and examine their 
asymptotic properties. Conclusions are presented in Section 5 and the proofs of the properties and theorems are in the appendix.

\section{Literature review}

Stock prices should reflect a retinal forecast of the present value of future dividends. However, the efficient market hypothesis has been traditionally associated with the assertion that future price changes are unpredictable or, in other words, efficient capital markets have no memory. Since Bachelier [2] has first advanced the concept of efficient market and used the random walk model for stock prices, financial economists have been examining the validity of the random walk model for stock prices. Ever since researchers, such as Working [52], Cowles and Jones [12], Kendall [35], Roberts [46], and Fama [21], have been testing whether stock prices follow a random walk model by examining whether the horizon returns for successive price changes are autocorrelated in the short horizon or not. Some of these studies conclude that the random walk model could not be rejected.

However, in many other studies, stock prices do not conform to the random walk process for stock prices; for example, Merton [41] shows that the changes in the variance of a stock's return can be predicted from its variance in the recent past. The existence of many anomalies, for example, the January effect (Keim [34] and Barone [3]) and the weekend effect (French [25]), violate the random walk hypothesis for stock prices. In addition, the positive autocorrelation of stock returns over intervals under a year and negative autocorrelation over longer intervals have been interpreted as an evidence of mean reverting behavior in stock prices. The predictable changes of current stock prices in the opposite direction in the coming years suggest that there are large and persistent transitory deviations from equilibrium. Under a closely related methodology based on autoregression, MacKinlay and Ramaswamy [40] find significant negative first-order autocorrelation in normalized intraday basis changes of the S\&P 500 index futures traded on the Chicago Mercantile Exchange.

Some researchers suggest that stock prices are not random but mean-reverted, which implies that stock returns could be predicted from past returns. For example, Fama and French [23] report that about $40 \%$ of the variation of 3-5 year returns can be predicted from past returns because of the mean reversion in US stock prices. They also document negative autocorrelations in long-horizon return in the portfolios of NYSE-listed stocks, which suggest that long-horizon future returns are predictable based on past returns and risk premia can generate mean reversion in equilibrium. Kim et al. [36] find that mean reversion in stock prices is strong in the pre-war period and is weaker in the post-war one; and interpret their findings as an evidence of a fundamental change in the stock returns process. Bessembinder et al. [5] detect greater magnitude of mean reversion in financial asset prices of agricultural commodities and crude oil, and substantially less but still statistically significant degree of mean reversion for metals. Cecchetti et al. [8], Bekaert and Hodrick [4], and Frennberg and Hansson [27] also analyze the mean reversion in stock prices as well as in GNP. Besides the above mean reversion processes, different mean reversion processes have also been proposed (Conrad and Kaul [11], Durlauf [19]). 
Mean reversion could be explained by the overreaction hypothesis defined by De Bondt and Thaler [15] who suggest that extreme movements in stock prices are followed by movements in the opposite direction to "correct" the initial overreaction and that the greater the magnitude of initial price change, the more extreme the offsetting reaction. The idea of fads in investor attitudes may affect stock prices and as long as prices have any tendency to gravitate back to fundamentals, they will be mean-reverting over long horizons (Werner et al. [16]). To support their claim, they find that in a long-term perspective (3-7 years) stock returns display significant negative serial correlations. Poterba and Summers [44] also find strong mean reversion over long-time horizons, with a display of negative serial correlation at long horizons but positive serial correlation over short horizons. To model mean reversion, Summers [49] hypothesizes that the logarithm of the stock prices follows the fads model which consists of a permanent component following a random walk model and a temporary component following a stationary $\mathrm{AR}(1)$ model. A GMR model, for example, see Eckbo and Liu [20] and Daniel [14], is the extension of the fads model in which the temporary component follows a general ARMA stationary process.

Random walk properties of stock price series have long been prominent in the studies of the stock return generating process (Summers [49], Fama and French [23], Lo and MacKinlay [39], Liu and He [38]). There are many statistics that can be used to test the random walk hypothesis, for example, the Box-Pierce $Q$ test and the DickeyFuller unit root tests. However, despite their superiority over serial correlations, the unit root tests developed by Dickey and Fuller $[17,18]$ fail to detect some important departures from the random walk model. Variance ratio tests originated from the pioneer works of Cochrane [10] and Lo and MacKinlay [39] with its methodology updated and expanded by Chow and Denning [9] have been found to be a better alternative to these tests. For example, Liu and He [38] find that the variance ratio test is heteroscedasticity-consistent and can accept overlapping data, which makes it a more reliable test than the Box-Pierce $Q$ test and a more powerful test than both the Box-Pierce $Q$ test and the Dickey-Fuller tests against hypotheses such as the $\operatorname{AR}(1), \operatorname{ARIMA}(1,1,1)$, and $\operatorname{ARIMA}(1,1,0)$. As such, the variance ratio test has been widely used in finance, for example, Oldfield and Rogalski [43], French and Roll [26], and Jones et al. [33] apply it to the relation between trading day and overnight return volatilities, Ronen [47] tests it on per-hour variances and finds that they are equal during trading and nontrading hours, and Lee and Mathur [37] use it to examine the efficiency in futures markets.

If a stock price follows a random walk with its generating process dominated by permanent components, it has no mean reversion tendency. The empirical evidence of the random walk properties is mixed. To support the random walk hypothesis, Ayadi and Pyun [1] apply the same test to stocks in the Korean Stock Exchange and show that after adjusting the serial correlation and heteroscedasticity, the random walk hypothesis cannot be rejected. Campbell et al. [7] see no objection to the random walk hypothesis in US stock market. Ojah and Karemera [42] apply the multiple variance ratio test developed by Chow and Denning [9] and show that equity prices in major Latin American emerging equity markets follow a random walk model and conclude that international investors in 
these markets cannot use historical information to design systematically profitable trading schemes because future long-term returns are not dependent on past returns.

On the other hand, Poterba and Summers [44] reject the random walk hypothesis and document that developed capital markets' stock returns exhibit positive autocorrelation over short horizons and mean reversion over long horizons. Liu and $\mathrm{He}$ [38] reject the random walk hypothesis under homoscedasticity and heteroscedasticity for five weekly exchange rates and suggest autocorrelations of weekly increments in the nominal exchange rate series, while Urrutia [50] uses a variance ratio test to document the dynamics that are inconsistent with the random walk model. Fong et al. [24] indicate that the martingale model works well for exchange rates of the floating-rate regime. Nevertheless, Gilmore and McManus [28] apply the variance ratio tests and obtain mixed results concerning the random walk properties of the stock indexes of the central European equity markets.

\section{The theory}

Let $p_{t}$ be the logarithm of the stock price under consideration at time $t$. The random walk model for stock price is one of the oldest parsimonious models in finance that hypothesizes $p_{t}$ to follow the recursive equation such that

$$
p_{t}=\mu+p_{t-1}+\eta_{t}
$$

where $\mu$ is a drift parameter and the usual stochastic assumption on $\eta_{t}$ is that it is a white noise process of a Gaussian error structure with mean zero and constant variance. Many studies have rejected the random walk model for stock prices and support the meanreverting process by which long-horizon future returns are predictable based on past returns. A simple mean reversion model is the fads model (Summers [49]) which consists of a permanent component $q_{t}$ and a temporary component $z_{t}$ such that

$$
p_{t}=z_{t}+q_{t}, \quad q_{t}=\mu+q_{t-1}+\eta_{t}, \quad z_{t}=\phi_{z_{t-1}}+\zeta_{t},
$$

in which $q_{t}$ and $z_{t}$ are independent, $q_{t}$ is a random walk with a drift, $z_{t}$ follows a stationary $\operatorname{AR}(1)$ model, the disturbances $\left\{\eta_{t}\right\}$ and $\left\{\zeta_{t}\right\}$ are serially, mutually, and cross-sectionally independent at all nonzero leads and lags. This could be improved from testing nonrandom walk alternative to the fads alternative such that

$H_{0}: p_{t}$ follows a random walk model versus $H_{1}: p_{t}$ follows a fads model.

The GMR model (Eckbo and Liu [20] and Daniel [14]) is the extension of the fads model in which $z_{t}$ follows a stationary ARMA process. The evidence that stock prices will be mean-reverting over long horizons and displaying significant negative serial correlations over years suggests that a simple fads model may not be able to capture the mean-reverting process over long horizons. The GMR model extends the fads model, in which the temporary component follows an ARMA stationary process. In this paper, we test the following hypotheses:

$H_{0}: p_{t}$ follows a random walk model versus $H_{1}: p_{t}$ follows a GMR model. 
To develop statistics for the above hypotheses, we first define the continuous component $k$-period return, $r_{t}^{k}$, and the continuous component $k$-period change, $s_{t}^{k}$, respective at time $t$ for the stationary component $z_{t}$ to be

$$
r_{t}^{k}=p_{t}-p_{t-k}, \quad s_{t}^{k}=z_{t}-z_{t-k} .
$$

Under the GMR process, it is easy to show that

$$
r_{t}^{k}=s_{t}^{k}+k \mu+\sum_{i=0}^{k-1} \eta_{t-i}
$$

Notice that $s_{t}^{k}$ is stationary for any $k$ as $z_{t}$ is stationary. We define

$$
a_{i}=\operatorname{corr}\left(z_{t}, z_{t-i}\right), \quad b_{1}^{k}=\operatorname{corr}\left(s_{t+k}^{k}, s_{t}^{k}\right), \quad \rho_{1}^{k}=\operatorname{corr}\left(r_{t+k}^{k}, r_{t}^{k}\right),
$$

where $\rho_{1}^{k}$ can be expressed as

$$
\rho_{1}^{k}=\frac{\rho_{1}+2 \rho_{2}+\cdots+k \rho_{k}+(k-1) \rho_{k+1}+\cdots+\rho_{2 k-1}}{k+2\left[(k-1) \rho_{1}+\cdots+\rho_{k-1}\right]} .
$$

In the GMR model, the transitory component $z_{t}$ possesses the following two properties.

Property 3.1. For any ARMA stationary process $z_{t}$, the first-order autocorrelation of its $k$-period change will tend to be minus half as $k$ tends to infinity. That is,

$$
\lim _{k \rightarrow \infty} b_{1}^{k}=-\frac{1}{2}
$$

Property 3.2. For any ARMA stationary process, the limit of the $k$ th-order autocorrelation will be zero, that is, $\lim _{k \rightarrow \infty} a_{k}=0$.

The proof of Property 3.1 is straightforward. The proof of Property 3.2 is in the appendix. The above two properties concerning the stationary component in the GMR model can be used to derive the following theorem concerning the first-order autocorrelation of the $k$-period returns and the variance ratio test for the GMR model.

THeORem 3.3. For the GMR model, there exists an integer $k_{0}$ such that the first-order autocorrelation, $\rho_{1}^{k}$, of the $k$-period returns, $r_{t}^{k}$, will be negative for all $k \geq k_{0}$. That is, $\rho_{1}^{k}<0$ for all $k \geq k_{0}$.

Refer to the appendix for the proof of Theorem 3.3. This theorem asserts that if the stock price is mean-reverted, it would exhibit negative autocorrelations for long-horizon returns. But with the fads model, the stock returns will exhibit negative serial correlation in a short horizon; see for example Jegadeesh [31]. For short-horizon returns, there is no restriction on the signs of the first-order autocorrelations in the GMR process. To test the GMR process against the random walk process using autocorrelations, we should focus on the autocorrelations of the long-horizon instead of short-horizon returns and test whether the autocorrelations are negative. 
The variance ratio test developed by Lo and MacKinlay [39] for $k$-period is defined as $1 / k$ times the ratio of the variance of the $k$ th lag difference of a series to that of the first lag difference such that

$$
\operatorname{VR}(k, 1)=\frac{\operatorname{var}\left(r_{t}^{k}\right) / k}{\operatorname{var}\left(r_{t}\right) / 1},
$$

where $r_{t}^{k}$ and $r_{t}$ are defined in (3.5). Under the random walk hypothesis, the increments in asset price series are serially uncorrelated, and hence the return variance will be proportional to the return horizon and the variance ratio $\operatorname{VR}(k, 1)$ will be 1 , while with the mean reversion alternative, $\operatorname{VR}(k, 1)$ will fall below 1 due to the negatively serial correlation of the return series. The variance ratio test exploits the fact that the variance of the increments in a random walk is linear in the sampling interval such that if a series follows a random walk model, the variance of its $k$-differences would be $k$ times the variance of its first differences. Hence, the hypothesis to test random walk against non-random walk is equivalent to the hypothesis to test $\operatorname{VR}(k, 1)=1$ against $\operatorname{VR}(k, 1) \neq 1$.

Theorem 3.3 suggests that this variance ratio test may not be a suitable test for the GMR model versus the random walk model. Before developing the new variance ratio tests for this purpose, we first introduce the following theorems for the variance ratio test.

THEOREM 3.4. For the GMR model, there exists an integer $k$ such that the variance ratio for the return series would be less than one for all $k \geq k_{0}$ that is, $\operatorname{VR}(k, 1)<1$ for all $k \geq k_{0}$ where $\operatorname{VR}(k, 1)$ is defined in (3.10).

THeOREM 3.5. For a GMR process, when $k$ is large enough, the variance ratio $\operatorname{VR}(k, 1)$ will decrease as $k$ increases. Thus, for sufficiently large $k, \operatorname{VR}(k, 1)>\operatorname{VR}(k+1,1)$, that is, $\operatorname{VR}(k, 1)$ decreases as $k$ increases.

Refer to the appendix for the proofs of Theorems 3.4 and 3.5. Theorem 3.4 states that the variance ratio for long-horizon returns should be less than one. However, for the GMR model, it is not necessary for the short-horizon returns to have a variance ratio less than 1. This is different from the findings for the fads model, see Jegadeesh [31]. This theorem suggests that for testing of the mean reversion process, one should focus on the variance ratios of long-horizon returns and test whether they are less than one. In the literature, there are several variance ratio tests, for example, Hays et al. [29] and Daniel [14]. But in this paper, we provide an alternative approach of using the variance ratio test to test whether a time series, for example, stock prices or stock index, follows the GMR model or the random walk model, and this is discussed in the next section.

\section{New variance ratio tests}

Using the properties of the autocorrelation and variance ratio statistics for the GMR model, we construct three new variance ratios tests to test whether stock prices follow the random walk or the GMR model. The first test is constructed based on Theorem 3.3 and the other two tests on the subsequent two theorems. Testing the random walk process against the GMR process is equivalent to testing whether the first-order autocorrelations 
of long-horizon returns are zero or negative, as in the following hypotheses:

$$
\begin{gathered}
H_{0}: \rho_{1}^{k}=0, \quad \forall k, \\
H_{1}: \rho_{1}^{k}<0, \quad \text { for large } k .
\end{gathered}
$$

To test the above hypotheses, we first define

$$
I_{i}^{(1)}= \begin{cases}1, & \hat{\rho}_{1}^{k_{i}}<0, i=1,2, \ldots, m, \\ 0, & \text { otherwise }\end{cases}
$$

where $\hat{\rho}_{1}^{k_{i}}$ is the sample first-order autocorrelation for $k_{i}$-period returns, $i=1,2, \ldots, m$, as defined in (3.7) and can be computed by (3.8). We then define

$$
T_{q}^{(1)}=\sum_{i=q}^{m} I_{i}^{(1)}=\sum a_{i}^{(q)} I_{i}^{(1)}
$$

where

$$
a_{i}^{(q)}= \begin{cases}1, & i \geq q, \\ 0, & \text { otherwise }\end{cases}
$$

and obtain the following theorem.

THEOREM 4.1. The statistic $T_{q}^{(1)}$ is asymptotically normal distributed with mean, variance, and covariance:

$$
\begin{gathered}
\operatorname{asy} \cdot E\left(T_{q}^{(1)}\right)=\sum_{i=1}^{m} a_{i}^{(q)} \text { asy } \cdot E\left(I_{i}\right)=\frac{1}{2} \sum_{i=1}^{m} a_{i}^{(q)}, \\
\operatorname{asy} \cdot \operatorname{var}\left(T_{q}^{(1)}\right)=\frac{1}{2 \pi} \sum_{i=1}^{m} \sum_{j=1}^{m} a_{i}^{(q)} a_{j}^{(q)} \tan ^{-1}\left[\frac{\rho_{i j}^{(1)}}{\sqrt{1-\left\{\rho_{i j}^{(1)}\right\}^{2}}}\right], \\
\text { asy } \cdot \operatorname{cov}\left(T_{q}^{(1)}, T_{q}^{(1)}\right)=\frac{1}{2 \pi} \sum_{i=1}^{m} \sum_{j=1}^{m} a_{i}^{(q)} a_{j}^{(q)} \tan ^{-1}\left[\frac{\rho_{i j}^{(1)}}{\sqrt{1-\left\{\rho_{i j}^{(1)}\right\}^{2}}}\right] .
\end{gathered}
$$

Refer to the appendix for the proof of Theorem 4.1. The value of $q$ determines the starting point for the negative first-order autocorrelation. Obviously, a large value of $T_{q}^{(1)}$ will favor the mean reversion alternative. However, there is no prior knowledge about what $q$ should be, so it is hard to predetermine the value of $q$, say $q=1,2, \ldots, m$. To overcome this problem, we construct $T_{q}^{(1)}$ for a set of predetermined values of $q$. The random walk hypothesis will be rejected if at least one of $T_{q}^{(1)}$ is significantly large, and will be accepted if all of them are not significantly large. The test statistic for (4.1) is

$$
Z^{(1)}=\max _{1 \leq q \leq m}\left|z_{q}^{(1)}\right|,
$$


where $z_{q}^{(1)}$ are the standardized values of the set of statistics $\left\{T_{q}^{(1)} \mid q=1,2, \ldots, m\right\}$ such that

$$
z_{q}^{(1)}=\frac{T_{q}^{(1)}-\operatorname{asy} \cdot E\left(T_{q}^{(1)}\right)}{\sqrt{\operatorname{asy} \cdot \operatorname{var}\left(T_{q}^{(1)}\right)}} .
$$

With the above asymptotic expectations and variances of the set of statistics $T_{q}^{(1)}$, the set of standardized statistics $z_{q}^{(1)}$ can be computed by using (4.7). Note that as the asymptotic distribution of the vector of the standardized statistics is multivariate normal with a zero mean vector under the null hypothesis, the test statistic $Z^{(1)}$ which is the maximum of the set of standardized statistics can then be obtained. We will discuss at the end of this section the testing procedure of using $Z^{(1)}$.

Testing the random walk process against the GMR process is also equivalent to testing whether the variance ratios for long-horizon returns are equal to one or smaller than one, such that

$$
\begin{cases}H_{0}: \operatorname{VR}(k, 1)=1, & \text { for all large } k, \\ H_{1}: \operatorname{VR}(k, 1)<0, & \text { for some large } k .\end{cases}
$$

To address these hypotheses, we define

$$
I_{i}^{(2)}= \begin{cases}1, & \mathrm{VR}\left(k_{i}, 1\right)-1<0, i=1,2, \ldots, m, \\ 0, & \text { otherwise }\end{cases}
$$

where $\mathrm{V} \widehat{\mathrm{R}}\left(k_{i}, 1\right)$ is the estimated variance ratio of the $k_{i}$-period return to 1 -period return, $i=1,2, \ldots, m$, which can be written as a linear combination of the autocorrelations of the 1-period return series (Cochrane [10]):

$$
\mathrm{V} \hat{\mathrm{R}}(k, 1)=1+\frac{2}{k} \sum_{j=1}^{k-1}(k-j) \hat{\rho}_{j},
$$

where $\rho_{j}$ is the $j$ th-order autocorrelation of 1 -period return. Postulating

$$
T_{q}^{(2)}=\sum_{i=q}^{m} I_{i}^{(2)}=\sum_{i=q}^{m} a_{i}^{(q)} I_{i}^{(2)},
$$

where $a_{i}^{(q)}$ is defined in (4.4), we obtain the following theorem. 
Theorem 4.2. The statistic $T_{q}^{(2)}$ is asymptotically normal distributed with mean, variance, and covariance:

$$
\begin{aligned}
& \text { asy } \cdot E\left(T_{q}^{(2)}\right)=\frac{1}{2} \sum_{i=1}^{m} a_{i}^{(q)} \\
& \text { asy } \cdot \operatorname{var}\left(T_{q}^{(2)}\right)=\frac{1}{2 \pi} \sum_{i=1}^{m} \sum_{j=1}^{m} a_{i}^{(q)} a_{j}^{(q)} \tan ^{-1}\left[\frac{\rho_{i j}^{(2)}}{\sqrt{1-\left\{\rho_{i j}^{(2)}\right\}^{2}}}\right] \text {, } \\
& \operatorname{asy} \cdot \operatorname{cov}\left(T_{q}^{(2)}, T_{q}^{(2)}\right)=\frac{1}{2 \pi} \sum_{i=1}^{m} \sum_{j=1}^{m} a_{i}^{(q)} a_{j}^{(q)} \tan ^{-1}\left[\frac{\rho_{i j}^{(2)}}{\sqrt{1-\left\{\rho_{i j}^{(2)}\right\}^{2}}}\right] \text {. }
\end{aligned}
$$

Refer to the appendix for the proof of Theorem 4.2. Note that the value of $q$ determines the starting point for the variance ratio when the variance ratio is smaller than one. Obviously, a large value of $T_{q}^{(2)}$ will favor the mean reversion alternative. Following the argument for the consideration of the test statistic in the first test, the test statistic of this test should be

$$
Z^{(2)}=\max _{1 \leq q \leq m}\left|z_{q}^{(2)}\right|
$$

where $z_{q}^{(2)}$ are the standard values of the set of statistics $\left\{T_{q}^{(2)} \mid q=1,2, \ldots, m\right\}$ under the null hypothesis, such that

$$
z_{q}^{(2)}=\frac{T_{q}^{(2)}-\operatorname{asy} \cdot E\left(T_{q}^{(2)}\right)}{\sqrt{\operatorname{asy} \cdot \operatorname{var}\left(T_{q}^{(2)}\right)}}
$$

With the asymptotic expectations and variances of the set of statistics $T_{q}^{(2)}$ stated in Theorem 4.2, the set of standardized statistics $z_{q}^{(2)}$ can be computed by using (4.14) and thereafter the test statistic $Z^{(2)}$ can be computed. We will discuss at the end of this section the testing procedure using the test statistic $Z^{(2)}$.

Alternatively, testing the random walk process against the GMR process is equivalent to testing whether the variance ratios are the same or decreasing for long-horizon returns, such that

$$
\begin{cases}H_{0}: \operatorname{VR}(k+1,1)=\operatorname{VR}(k, 1), & \text { for all large } k, \\ H_{1}: \operatorname{VR}(k+1,1)<\operatorname{VR}(k, 1), & \text { for some large } k .\end{cases}
$$

To address these hypotheses, we first define

$$
I_{i}^{(3)}= \begin{cases}1, & \mathrm{VR}\left(k_{i+1}, 1\right)-\mathrm{V} \hat{\mathrm{R}}\left(k_{i}, 1\right)<0, i=1,2, \ldots, m-1, \\ 0, & \text { otherwise }\end{cases}
$$


where $\mathrm{V} \hat{\mathrm{R}}\left(k_{i+1}, 1\right)$ and $\mathrm{V} \hat{\mathrm{R}}\left(k_{i}, 1\right)$ are the estimated variance ratios of $k_{i+1}$-period returns and $k_{i}$-period returns to 1 -period returns, $i=1,2, \ldots, m-1$, which can be computed by using (4.10). We also construct

$$
T_{q}^{(3)}=\sum_{i=q}^{m-1} I_{i}^{(3)}=\sum_{i=1}^{m-1} a_{i}^{(q)} I_{i}^{(3)},
$$

where $a_{i}^{(q)}$ is defined in (4.4). Here, the value of $q$ determines the starting point for the decreasing trend in the variance ratios. Same as the argument of the above two tests, a large value of $T_{q}^{(3)}$ will favor the mean reversion alternative.

THEOREM 4.3. The statistic $T_{q}^{(3)}$ is asymptotically normal distributed with mean, variance, and covariance:

$$
\begin{aligned}
& \operatorname{asy} \cdot E\left(T_{q}^{(3)}\right)=\frac{1}{2} \sum_{i=1}^{m-1} a_{i}^{(q)} \\
& \operatorname{asy} \cdot \operatorname{var}\left(T_{q}^{(3)}\right)=\frac{1}{2 \pi} \sum_{i=1}^{m-1} \sum_{j=1}^{m-1} a_{i}^{(q)} a_{j}^{(q)} \tan ^{-1}\left[\frac{\rho_{i j}^{(3)}}{\sqrt{1-\left\{\rho_{i j}^{(3)}\right\}^{2}}}\right] \text {, } \\
& \operatorname{asy} \cdot \operatorname{cov}\left(T_{q}^{(3)}, T_{q}^{(3)}\right)=\frac{1}{2 \pi} \sum_{i=1}^{m-1} \sum_{j=1}^{m-1} a_{i}^{(q)} a_{j}^{(q)} \tan ^{-1}\left[\frac{\rho_{i j}^{(3)}}{\sqrt{1-\left\{\rho_{i j}^{(3)}\right\}^{2}}}\right] \text {. }
\end{aligned}
$$

Refer to the appendix for the proof of Theorem 4.3. Since there is no prior knowledge about what $q$ should be, we set the test statistic of this test as

$$
Z^{(3)}=\max _{1 \leq q \leq m}\left|z_{q}^{(3)}\right|
$$

where $z_{q}^{(3)}$ are the standardized values of the set of statistics $\left\{T_{q}^{(3)} \mid q=1,2, \ldots, m-1\right\}$ under the null hypothesis, such that

$$
z_{q}^{(3)}=\frac{T_{q}^{(3)}-\operatorname{asy} \cdot E\left(T_{q}^{(3)}\right)}{\sqrt{\operatorname{asy} \cdot \operatorname{var}\left(T_{q}^{(3)}\right)}} .
$$

With the above asymptotic expectations and variances of the set of statistics $T_{q}^{(3)}$, the set of standardized statistics $z_{q}^{(3)}$ can be computed by using (4.20), and the asymptotic null distribution of the test statistic $Z^{(3)}$ can be constructed using the simulation method.

We now turn to discuss the testing procedure of using the statistics $Z^{(1)}, Z^{(2)}$, and $Z^{(3)}$ defined in (4.6), (4.13), and (4.19). For simplicity, we let $Z^{(i)}$ to be $T_{1}$ and $z_{q}^{(i)}$ to be $z_{q}$ for $i=1,2$ and 3 and $q=1,2, \ldots, m$. Thus, (4.6), (4.13), and (4.19) become

$$
T_{1}=\max _{1 \leq i \leq m}\left|z\left(k_{i}\right)\right|
$$


Applying the probability inequality in Sidak [48], we obtain the following inequality for a set of $m$ independent standard normal variates, $\left(Z_{1}, Z_{2}, \ldots, Z_{m}\right)$ :

$$
\operatorname{Pr}\left[\max \left(\left|z_{1}\right|,\left|z_{2}\right|, \ldots,\left|z_{m}\right|\right) \leq Z_{\alpha^{+} / 2}\right] \geq(1-\alpha),
$$

where $\alpha^{+}=1-(1-\alpha)^{1 / m}$.

Hochberg [30] proves that under the condition that the set of $m$ standard normal variates, $z_{i}$ 's, are correlated with an arbitrary correlation matrix $\Omega$, the following inequality holds:

$$
\operatorname{Pr}\left[\max \left(\left|z_{1}\right|,\left|z_{2}\right|, \ldots,\left|z_{m}\right|\right) \leq \operatorname{SMM}(\alpha ; m ; T)\right] \geq(1-\alpha)
$$

where $\operatorname{SMM}(\alpha ; m ; T)$ is the upper $\alpha$ point of the studentized maximum modulus (SMM) distribution with parameter $m$ and $T$ (the sample size) degrees of freedom. Asymptotically, when $T=\infty$, the Hochberg inequality is equivalent to the Sidak inequality with $\operatorname{SMM}(\alpha ; m ; \infty)=Z_{\alpha^{+} / 2}$. Combining the above results, the following inequality holds asymptotically:

$$
\operatorname{Pr}\left[T_{1} \leq \operatorname{SMM}(\alpha ; m ; \infty)\right] \geq(1-\alpha)
$$

The asymptotic SMM critical value can be calculated from the conventional standard normal distribution, that is, $\operatorname{SMM}(\alpha ; m ; \infty)=Z_{\alpha^{+} / 2}$. By comparing $T_{1}$ with the calculated SMM critical value, the random walk hypothesis versus the GMR model can then be tested. We note that the multiple tests, for example, the multiple variance ratio test developed by Chow and Denning [9], usually follow the SMM distribution (Richmond [45]).

\section{Concluding remarks}

Lo and MacKinlay [39] introduce the variance ratio test to test the hypothesis of the random walk to reflect market efficiency against the alternative of the non-random walk model to reflect market inefficiency. However, the non-random walk model could be too general and thus it does not reflect the complexity of stock return behavior which may follow the GMR process, containing components of both random walk model and nonrandom walk model. In this paper, we develop some properties for the GMR process. Using these properties, we extend the variance ratio tests developed by Lo and MacKinlay [39] to three new nonparametric tests comparing the relative variability of returns over different horizons to test the GMR model as an alternative to the random walk model and examine the asymptotic properties of these tests. We will study the power and the size of our proposed variance ratio tests, and compare their performance with some wellknown variance ratio tests by simulation and by an illustration with a well-known real-life example in a separate paper.

In the literature, there are several modifications and refinements made to the variance ratio tests or the ways of using them. For example, Cressie [13] uses the standardized variogram, that is, $k$ times the variance ratio plotted against $k$, as a graphical procedure for determining the nonstationarity in time series, Westfall [51] modifies the variance ratio statistics to obtain the correct asymptotic level of significance for nonnormal data, 
and Chow and Denning [9] develop a simple multiple variance ratio test. Fong et al. [24] develop joint variance ratio tests to assess the martingale hypothesis for exchange rates while Ronen [47] modifies the variance ratio tests across trading and nontrading periods by using the generalized method of moments. In addition, Wright [53] proposes using variance ratio tests based on ranks and signs of a time series to test the null hypothesis that the series is a martingale difference sequence. Recently, Busetti and Taylor [6] develop a new statistic to test the hypothesis of stochastic stationarity in time series characterized by variance shifts at some point in the sample. Further research includes applying our approach to the above studies to test the GMR model in place of the non-random walk model or the fads model.

\section{Appendix}

Proof of Property 3.2. Recall that any $\operatorname{ARMA}(p, q)$ stationary process can be represented by

$$
\phi_{p}(B) z_{t}=\theta_{q}(B) \varepsilon_{t},
$$

where $\phi_{p}(B)=1-\phi_{1} B-\cdots-\phi_{p} B^{p}$ and $\theta_{q}(B)=1-\theta_{1} B-\cdots-\theta_{q} B^{q}$. Thus, for sufficiently large $k$, we have

$$
a_{k}=\phi_{1} a_{k-1}+\phi 2 a_{k-2}+\cdots+\phi_{p} a_{k-p}
$$

It is well known that the above equation can be expressed in the following form:

$$
a_{k}=\sum_{i=1}^{p} A_{i} G_{i}^{k}
$$

where $G_{i}^{-1}$ 's are the roots of the difference equation $\phi_{p}(B)=0$, and all $A_{i}$ 's are constants. For any stationary process, we have $\left|G_{i}^{-1}\right|>1$ and $\left|G_{i}\right|<1$ and hence

$$
\lim _{k \rightarrow \infty} k a_{k}=\sum_{i=1}^{p} A_{i}\left\{\lim _{k \rightarrow \infty} k G_{i}^{k}\right\}=0
$$

which implies that $\lim _{k \rightarrow \infty} a_{k}=0$.

Proof of Theorem 3.3. As $z_{t}$ and $q_{t}$ are independent, for large $k$, the first-order autocorrelation of the $k$-period returns can be expressed in the following:

$$
\begin{aligned}
\rho_{1}^{k} & =\frac{\operatorname{cov}\left(r_{t+k}^{k}, r_{t}^{k}\right)}{\operatorname{var}\left(r_{t}^{k}\right)}=\frac{\operatorname{cov}\left(s_{t+k}^{k}+k \mu+\sum_{i=0}^{k-1} \eta_{t+k-i}, s_{t}^{k}+k \mu+\sum_{i=0}^{k-1} \eta_{t-i}\right)}{\operatorname{var}\left(s_{t}^{k}+k \mu+\sum_{i=0}^{k-1} \eta_{t-i}\right)} \\
& =\frac{\operatorname{cov}\left(s_{t+k}^{k}, s_{t}^{k}\right)}{\operatorname{var}\left(s_{t}^{k}\right)+k \sigma_{\eta}^{2}}=\frac{b_{1}^{k} \operatorname{var}\left(s_{t}^{k}\right)}{\operatorname{var}\left(s_{t}^{k}\right)+k \sigma_{\eta}^{2}} .
\end{aligned}
$$

From Property 3.1, we have $\lim _{k \rightarrow \infty} b_{1}^{k}=-1 / 2$. Hence, $\rho_{1}^{k}<0$ for all significant large $k$. 
Proof of Theorem 3.4. Since

$$
\begin{aligned}
\operatorname{var}\left(r_{t}^{k}\right) & =\operatorname{var}\left(s_{t}^{k}+k \mu+\sum_{i=0}^{k-1} \eta_{t-i}\right)=\operatorname{var}\left(s_{t}^{k}\right)+k \sigma_{\eta}^{2}, \\
\operatorname{var}\left(s_{t}^{k}\right) & =\operatorname{var}\left(z_{t}-z_{t-k}\right)=\operatorname{var}\left(z_{t}\right)+\operatorname{var}\left(z_{t-k}\right)-2 \operatorname{cov}\left(z_{t}, z_{t-k}\right) \\
& =2 \operatorname{var}\left(z_{t}\right)-2 \operatorname{cov}\left(z_{t}, z_{t-k}\right)=2\left(1-a_{k}\right) \sigma_{z}^{2},
\end{aligned}
$$

we have

$$
\begin{aligned}
\operatorname{VR}(k, 1)= & \frac{\operatorname{var}\left(r_{t}^{k}\right) / k}{\operatorname{var}\left(r_{t}\right) / 1}=\frac{\left\lfloor\operatorname{var}\left(s_{t}^{k}\right)+k \sigma_{\eta}^{2}\right\rfloor / k}{\left[\operatorname{var}\left(s_{t}\right)+\sigma_{\eta}^{2}\right] / 1} \\
= & \frac{2\left(1-a_{k}\right) \sigma_{z}^{2}+k \sigma_{\eta}^{2}}{2\left(1-a_{1}\right) \sigma_{z}^{2}+k \sigma_{\eta}^{2}} \cdot \frac{1}{k}=1+\frac{2 \sigma_{z}^{2}\left[\left(1-a_{k}\right)-k\left(1-a_{1}\right)\right]}{k\left[2\left(1-a_{1}\right) \sigma_{z}^{2}+\sigma_{\eta}^{2}\right]} .
\end{aligned}
$$

Applying Property 3.2, for sufficiently large $k$, we have $\left(1-a_{k}\right)-k\left(1-a_{1}\right)<0$. Thus, $\operatorname{VR}(k, 1)<1$ for all sufficiently large $k$.

Proof of Theorem 3.5 .

$$
\begin{aligned}
\operatorname{VR}(k+1, k) & =\frac{\operatorname{var}\left(r_{t}^{k+1}\right) / k+1}{\operatorname{var}\left(r_{t}^{k}\right) / k}=\frac{\operatorname{var}\left(s_{t}^{k+1}\right)+(k+1) \sigma_{\eta}^{2}}{\operatorname{var}\left(s_{t}^{k}\right)+k \sigma_{\eta}^{2}} \cdot \frac{k}{k+1} \\
& =\frac{2\left(1-a_{k+1}\right) \sigma_{z}^{2}+(k+1) \sigma_{\eta}^{2}}{2\left(1-a_{k+1}\right) \sigma_{z}^{2}+k \sigma_{\eta}^{2}} \cdot \frac{k}{k+1} \\
& =1+\frac{2 k\left(1-a_{k+1}\right) \sigma_{z}^{2}+k(k+1) \sigma_{\eta}^{2}-2(k+1)\left(1-a_{k}\right) \sigma_{z}^{2}-k(k+1) \sigma_{\eta}^{2}}{\left[2\left(1-a_{k}\right) \sigma_{z}^{2}+k \sigma_{\eta}^{2}\right](k+1)} \\
& =1+\frac{2\left(-1-k a_{k+1}+(k+1) a_{k}\right) \sigma_{z}^{2}}{\left[2\left(1-a_{k}\right) \sigma_{z}^{2}+k \sigma_{\eta}^{2}\right](k+1)} .
\end{aligned}
$$

As

$$
\lim _{k \rightarrow \infty} 2\left(-1-k a_{k+1}+(k+1) a_{k}\right) \sigma_{z}^{2}=-2 \sigma_{z}^{2}, \quad \lim _{k \rightarrow \infty}\left[2\left(1-a_{k}\right) \sigma_{z}^{2}+k \sigma_{\eta}^{2}\right](k+1)=\infty,
$$

we have

$$
\lim _{k \rightarrow \infty} \operatorname{VR}(k+1, k)=1^{-} .
$$

Applying Theorem 3.4, for all sufficiently large $k$, we have $\operatorname{VR}(k+1,1)<1$.

Hence, $\operatorname{VR}(k+1,1)<\operatorname{VR}(k, 1)$. 
To prove Theorems 4.1 to 4.3 , we first define

$$
I_{i}= \begin{cases}1, & x_{i}<0, i=1,2, \ldots, m \\ 0, & \text { otherwise }\end{cases}
$$

where $\underline{X}=\left(x_{1}, x_{2}, \ldots, x_{m}\right)^{t} \stackrel{a}{\sim} N(0, \Sigma), \Sigma=\left\{\sigma_{i j}\right\}$, and obtain the following property.

Property A.1. For $I_{i}$ defined in (A.11), we have

$$
\begin{gathered}
\text { asy } \cdot E\left(I_{i}\right)=\frac{1}{2}, \quad \text { asy } \cdot \operatorname{var}\left(I_{i}\right)=\frac{1}{4}, \\
\operatorname{asy} \cdot \operatorname{cov}\left(I_{i}, I_{j}\right)=\frac{1}{2 \pi} \tan ^{-1}\left(\frac{\rho_{i j}}{\sqrt{1-\rho_{i j}^{2}}}\right),
\end{gathered}
$$

where

$$
\rho_{i j}=\operatorname{corr}\left(x_{i}, x_{j}\right)=\frac{\sigma_{i j}}{\sqrt{\sigma_{i i} \sqrt{\sigma_{j j}}}} .
$$

The proof of Property A.1 is straightforward and hence we skip presenting the proof which is available on request.

Property A.2. Under the random walk hypothesis, the asymptotic expected values, variances, and covariances for the set of estimated variance ratios $\left\{\mathrm{VR}\left(k_{i}, 1\right) \mid i=1,2, \ldots, m\right\}$ are as follows:

$$
\begin{gathered}
\operatorname{asy} \cdot E\left(\mathrm{~V} \hat{\mathrm{R}}\left(k_{i}, 1\right)\right)=1, \quad \operatorname{asy} \cdot \operatorname{var}\left(\mathrm{VR}\left(k_{i}, 1\right)\right)=\frac{2\left(k_{i}-1\right)\left(2 k_{i}-1\right)}{3 T k_{i}}, \\
\operatorname{asy} \cdot \operatorname{cov}\left(\mathrm{V} \hat{\mathrm{R}}\left(k_{i}, 1\right), \operatorname{V\hat {\mathrm {R}}}\left(k_{j}, 1\right)\right)=\frac{2}{3} \frac{\left(k_{i}-1\right)}{T k_{j}}\left(3 k_{j}-k_{i}-1 v\right), \quad i<j, \\
\sqrt{T}(\underline{\mathrm{V} \hat{\mathrm{R}}}-1) \stackrel{a}{\sim} N\left(\underline{0}, \Sigma_{2}\right),
\end{gathered}
$$

where $\underline{\mathrm{VR}}=\left(\mathrm{V} \hat{\mathrm{R}}\left(k_{1}-1\right), \operatorname{VR}\left(k_{2}-1\right), \ldots, \mathrm{VR}\left(k_{m}-1\right)\right)^{\prime}$ and $\Sigma_{2}=\left\{\sigma_{i j}^{(2)}\right\}$ with

$$
\sigma_{i i}^{(2)}=\frac{2\left(k_{i}-1\right)\left(2 k_{i}-1\right)}{3 k_{i}}, \quad \sigma_{i j}^{(2)}=\frac{2}{3} \frac{\left(k_{i}-1\right)}{k_{j}}\left(3 k_{j}-k_{i}-1\right) .
$$

These properties enable us to obtain the proofs of Theorems 4.1 to 4.3 shown as below. Proof of Theorem 4.1. Under the null hypothesis, $\hat{\rho}_{1}^{k_{i}}$ will be small and can be estimated by (3.8). It is well known that under the null hypothesis, the vector of the sample autocorrelation for the $i$-period returns has an asymptotic multivariate normal distribution such that

$$
\sqrt{T} \underline{\hat{\rho}} \stackrel{a}{\sim} N(\underline{0}, I)
$$


Hence, the asymptotic null distribution of $\hat{\rho}_{1}^{k_{i}}$ is

$$
\sqrt{T}{\underline{\hat{\rho}_{i}}}^{k} \stackrel{a}{\sim} N\left(\underline{0}, \sum_{1}\right)
$$

where $\hat{\rho}_{1}^{k}=\left(\hat{\rho}_{1}^{k_{1}}, \hat{\rho}_{1}^{k_{2}}, \ldots, \hat{\rho}_{1}^{k_{m}}\right)^{\prime}$ and $\sum_{1}=\left\{\sigma_{i j}^{(1)}\right\}$ with

$$
\begin{gathered}
\sigma_{i i}^{(1)}=\frac{2 k_{i}^{2}+1}{3 k_{i}}, \\
\sigma_{i j}^{(1)}= \begin{cases}\frac{k_{i}^{2}}{k_{j}}, & k_{j} \geq 2 k_{i}, \\
\frac{1}{3 k_{i} k_{j}}\left[k_{j}^{3}-6 k_{j}^{2} k_{i}+12 k_{j} k_{i}^{2}-5 k_{i}^{3}+2 k_{i}-k_{j}\right], & k_{i} \leq k_{j} \leq 2 k_{i} .\end{cases}
\end{gathered}
$$

Under the null hypothesis, using the above results and applying Property A.1, we obtain the following results:

$$
\begin{gathered}
\operatorname{asy} \cdot E\left(I_{i}^{(1)}\right)=\frac{1}{2}, \quad \operatorname{asy} \cdot \operatorname{var}\left(I_{i}^{(1)}\right)=\frac{1}{4}, \\
\operatorname{asy} \cdot \operatorname{cov}\left(I_{i}^{(1)}, I_{j}^{(1)}\right)=\frac{1}{2 \pi} \tan ^{-1}\left[\frac{\rho_{i j}^{(1)}}{\sqrt{1-\left\{\rho_{i j}^{(1)}\right\}^{2}}}\right],
\end{gathered}
$$

where

$$
\rho_{i j}^{(1)}=\operatorname{corr}\left(\hat{\rho}_{i}^{k_{i}}, \hat{\rho}_{1}^{k_{j}}\right)=\frac{\sigma_{i j}^{(1)}}{\sqrt{\sigma_{i i}^{(1)}} \sqrt{\sigma_{j j}^{(1)}}} .
$$

Note that $\rho_{i j}^{(1)}$ will not depend on $T$, the total number of observations in the returns series. Also, under the null hypothesis, the asymptotic expectations, variances, and covariances of the set of statistics, $T_{q}^{(1)}$, will then be

$$
\begin{aligned}
& \mathrm{asy} \cdot E\left(T_{q}^{(1)}\right)=\sum_{i=1}^{m} a_{i}^{(q)} \mathrm{asy} \cdot E\left(I_{i}\right)=\frac{1}{2} \sum_{i=1}^{m} a_{i}^{(q)}, \\
& \operatorname{asy} \cdot \operatorname{var}\left(T_{q}^{(1)}\right)=\sum_{i=1}^{m} \sum_{j=1}^{m} a_{i}^{(q)} a_{j}^{(q)} \operatorname{cov}\left(I_{i}^{(1)}, I_{j}^{(1)}\right) \\
& =\frac{1}{2 \pi} \sum_{i=1}^{m} \sum_{j=1}^{m} a_{i}^{(q)} a_{j}^{(q)} \tan ^{-1}\left[\frac{\rho_{i j}^{(1)}}{\sqrt{1-\left\{\rho_{i j}^{(1)}\right\}^{2}}}\right],
\end{aligned}
$$




$$
\begin{aligned}
\operatorname{asy} \cdot \operatorname{cov}\left(T_{q}^{(1)}, T_{q}^{(1)}\right) & =\operatorname{cov}\left[\sum_{i=1}^{m} a_{i}^{(q)} I_{i}^{(1)}, \sum a_{j}^{(q)} I_{j}^{(1)}\right]=\sum_{i=1}^{m} \sum_{j=1}^{m} a_{i}^{(q)} a_{j}^{(q)} \operatorname{cov}\left(I_{i}^{(1)}, I_{j}^{(1)}\right) \\
& =\frac{1}{2 \pi} \sum_{i=1}^{m} \sum_{j=1}^{m} a_{i}^{(q)} a_{j}^{(q)} \tan ^{-1}\left[\frac{\rho_{i j}^{(1)}}{\sqrt{1-\left\{\rho_{i j}^{(1)}\right\}^{2}}}\right] .
\end{aligned}
$$

Proof of Theorem 4.2. From Property A.2, under the random walk hypothesis, we obtain the asymptotic expected values, variances, and covariances for the set of estimated variance ratios $\left\{\mathrm{VR}\left(k_{i}, 1\right) \mid i=1,2, \ldots, m\right\}$. Using this result and applying Property A.1, we obtain the following results under the null hypothesis:

$$
\begin{gathered}
\operatorname{asy} \cdot E\left(I_{i}^{(2)}\right)=\frac{1}{2}, \quad \operatorname{asy} \cdot \operatorname{var}\left(I_{i}^{(2)}\right)=\frac{1}{4}, \\
\operatorname{asy} \cdot \operatorname{cov}\left(I_{i}^{(2)}, I_{j}^{(2)}\right)=\frac{1}{2 \pi} \tan ^{-1}\left[\frac{\rho_{i j}^{(2)}}{\sqrt{1-\left\{\rho_{i j}^{(2)}\right\}^{2}}}\right],
\end{gathered}
$$

where

$$
\rho_{i j}^{(2)}=\operatorname{corr}\left(\mathrm{V} \hat{\mathrm{R}}\left(k_{i}, 1\right), \mathrm{V} \hat{\mathrm{R}}\left(k_{j}, 1\right)\right)=\frac{\sigma_{i j}^{(2)}}{\sqrt{\sigma_{i i}^{(2)}} \sqrt{\sigma_{j j}^{(2)}}} .
$$

Note again that $\rho_{i j}^{(2)}$ will not depend on $T$, that is, the total number of observations in the returns series. Also, under the null hypothesis, the asymptotic expectations, variances, and covariances of the set of statistics, $T_{q}^{(2)}$ will be

$$
\begin{aligned}
& \operatorname{asy} \cdot E\left(T_{q}^{(2)}\right)=\frac{1}{2} \sum_{i=1}^{m} a_{i}^{(q)} \\
& \operatorname{asy} \cdot \operatorname{var}\left(T_{q}^{(2)}\right)=\frac{1}{2 \pi} \sum_{i=1}^{m} \sum_{j=1}^{m} a_{i}^{(q)} a_{j}^{(q)} \tan ^{-1}\left[\frac{\rho_{i j}^{(2)}}{\sqrt{1-\left\{\rho_{i j}^{(2)}\right\}^{2}}}\right] \text {, } \\
& \operatorname{asy} \cdot \operatorname{cov}\left(T_{q}^{(2)}, T_{q}^{(2)}\right)=\frac{1}{2 \pi} \sum_{i=1}^{m} \sum_{j=1}^{m} a_{i}^{(q)} a_{j}^{(q)} \tan ^{-1}\left[\frac{\rho_{i j}^{(2)}}{\sqrt{1-\left\{\rho_{i j}^{(2)}\right\}^{2}}}\right] \text {. }
\end{aligned}
$$


Proof of Theorem 4.3. From Property A.2, under the random walk hypothesis, we obtain the asymptotic expected values, variances, and covariances for the set of estimated variance ratios $\left\{\mathrm{VR}\left(k_{i}, 1\right) \mid i=1,2, \ldots, m\right\}$. Using this result and applying Property A.1, we obtain the following results under the null hypothesis:

$$
\begin{gathered}
\operatorname{asy} \cdot E\left(I_{i}^{(3)}\right)=\frac{1}{2}, \quad \text { asy } \cdot \operatorname{var}\left(I_{i}^{(3)}\right)=\frac{1}{4}, \\
\operatorname{asy} \cdot \operatorname{cov}\left(I_{i}^{(3)}, I_{j}^{(3)}\right)=\frac{1}{2 \pi} \tan ^{-1}\left[\frac{\rho_{i j}^{(3)}}{\sqrt{1-\left\{\rho_{i j}^{(3)}\right\}^{2}}}\right],
\end{gathered}
$$

where

$$
\begin{aligned}
\rho_{i j}^{(3)} & =\operatorname{corr}\left(\mathrm{V} \hat{\mathrm{R}}\left(k_{i+1}, 1\right)-\mathrm{V} \hat{\mathrm{R}}\left(k_{i}, 1\right), \mathrm{V} \hat{\mathrm{R}}\left(k_{j+1}, 1\right)-\mathrm{V} \hat{\mathrm{R}}\left(k_{j}, 1\right)\right) \\
& =\frac{\sigma_{i+1, j+1}^{(2)}-\sigma_{i+1, j}^{(2)}-\sigma_{i, j+1}^{(2)}+\sigma_{i, j}^{(2)}}{\sqrt{\sigma_{i+1, i+1}^{(2)}+\sigma_{i, i}^{(2)}-2 \sigma_{i+1, i}^{(2)} \sqrt{\sigma_{j+1, j+1}^{(2)}+\sigma_{j, j}^{(2)}-2 \sigma_{j+1, j}^{(2)}}}} .
\end{aligned}
$$

Thus, under the null hypothesis, the asymptotic expectations, variances, and covariances of the set of statistics, $T_{q}^{(3)}$, will be

$$
\begin{aligned}
& \text { asy } \cdot E\left(T_{q}^{(3)}\right)=\frac{1}{2} \sum_{i=1}^{m-1} a_{i}^{(q)}, \\
& \operatorname{asy} \cdot \operatorname{var}\left(T_{q}^{(3)}\right)=\frac{1}{2 \pi} \sum_{i=1}^{m-1} \sum_{j=1}^{m-1} a_{i}^{(q)} a_{j}^{(q)} \tan ^{-1}\left[\frac{\rho_{i j}^{(3)}}{\sqrt{1-\left\{\rho_{i j}^{(3)}\right\}^{2}}}\right] \text {, } \\
& \operatorname{asy} \cdot \operatorname{cov}\left(T_{q}^{(3)}, T_{q}^{(3)}\right)=\frac{1}{2 \pi} \sum_{i=1}^{m-1} \sum_{j=1}^{m-1} a_{i}^{(q)} a_{j}^{(q)} \tan ^{-1}\left[\frac{\rho_{i j}^{(3)}}{\sqrt{1-\left\{\rho_{i j}^{(3)}\right\}^{2}}}\right] \text {. }
\end{aligned}
$$

\section{References}

[1] O. F. Ayadi and C. S. Pyun, An application of variance ratio test to the Korean securities market, Journal of Banking and Finance 18 (1994), no. 4, 643-658.

[2] L. Bachelier, Théorie de la spéculation, Annales Scientifiques de l'École Normale Supérieure 17 (1900), 21-86.

[3] E. Barone, The Italian stock market: efficiency and calendar anomalies, Journal of Banking and Finance 14 (1990), no. 2-3, 483-510.

[4] G. Bekaert and R. J. Hodrick, Characterizing predictable components in excess return on equity and foreign exchange markets, Journal of Finance 47 (1992), 467-509. 
[5] H. Bessembinder, J. F. Coughenour, P. J. Seguin, and M. M. Smoller, Mean reversion in equilibrium asset prices: evidence from the futures term structure, Journal of Finance 50 (1995), no. 1, 361-375.

[6] F. Busetti and A. M. R. Taylor, Variance shifts, structural breaks, and stationarity tests, Journal of Business \& Economic Statistics 21 (2003), no. 4, 510-531.

[7] J. Y. Campbell, A. Lo, and A. C. McKinlay, The Econometrics of Financial Markets, Princeton University Press, New Jersey, 1997.

[8] S. G. Cecchetti, P. S. Lam, and N. C. Mark, Mean reversion in equilibrium asset prices, American Economic Review 80 (1990), no. 3, 398-418.

[9] V. K. Chow and K. C. Denning, A simple multiple variance ratio test: power and size in finite samples, Journal of Econometrics 58 (1993), no. 3, 385-401.

[10] J. H. Cochrane, How big is the Random Walk in GNP, Journal of Political Economy 96 (1988), 893-920.

[11] J. Conrad and G. Kaul, Mean reversion in short-horizon expected returns, Review of Financial Studies 2 (1989), no. 2, 225-240.

[12] A. Cowles and H. Jones, Some posteriori probabilities in stock market action, Econometrica 5 (1937), 280-294.

[13] N. Cressie, A graphical procedure for determining nonstationarity in time series, Journal of the American Statistical Association 83 (1988), no. 404, 1108-1116.

[14] K. D. Daniel, The power and size of mean reversion tests, Journal of Empirical Finance 8 (2001), no. 5, 493-535.

[15] W. F. M. De Bondt and R. H. Thaler, Does the stock market overreact?, Journal of Finance 40 (1985), 793-905.

[16] _ Anomalies: a mean-reverting walk down Wall Street, Journal of Economic Perspectives 3 (1989), no. 1, 189-202.

[17] D. A. Dickey and W. A. Fuller, Distribution of the estimators for autoregressive time series with a unit root, Journal of the American Statistical Association 74 (1979), no. 366, part 1, 427-431.

[18] Likelihood ratio statistics for autoregressive time series with a unit root, Econometrica 49 (1981), no. 4, 1057-1072.

[19] S. N. Durlauf, Time series properties of aggregate output fluctuations, Journal of Econometrics 56 (1993), no. 1-2, 39-56.

[20] B. E. Eckbo and J. Liu, Temporary components of stock prices: new univariate results, Journal of Financial and Quantitative Analysis 28 (1993), no. 2, 161-176.

[21] E. F. Fama, The behavior of stock market prices, Journal of Business 38 (1965), 34-105.

[22] __ Efficient capital markets: a review of theory and empirical work, Journal of Finance 25 (1970), 383-417.

[23] E. F. Fama and K. R. French, Permanent and temporary components of stock prices, Journal of Political Economy 96 (1988), no. 2, 246-273.

[24] W. M. Fong, S. K. Koh, and S. Ouliaris, Joint variance-ratio tests of the martingale hypothesis for exchange rates, Journal of Business \& Economic Statistics 15 (1997), no. 1, 51-60.

[25] K. R. French, Stock return and weekend effect, Journal of Financial Economics 8 (1980), no. 1, $55-69$.

[26] K. R. French and R. Roll, Stock return variances, the arrival of information and the reaction of traders, Journal of Financial Economics 17 (1986), no. 1, 5-26.

[27] P. Frennberg and B. Hansson, Testing the random walk hypothesis on Swedish stock prices: 19191990, Journal of Banking and Finance 17 (1993), no. 1, 5-26.

[28] G. C. Gilmore and G. M. McManus, Random-walk and efficiency tests of Central European equity markets, Managerial Finance 29 (2003), no. 4, 42-61. 
[29] P. Hays, M. Schreiber, J. E. Payne, B. T. Ewing, and M. J. Piette, Are net discount ratios stationary? Evidence of mean-reversion and persistence, Journal of Risk and Insurance 67 (2000), no. 3, 439449.

[30] Y. Hochberg, Some generalizations of the T-method in simultaneous inference, Journal of Multivariate Analysis 4 (1974), no. 2, 224-234.

[31] N. Jegadeesh, Seasonality in stock price mean reversion: evidence from the U.S. and the U.K, Journal of Finance 46 (1991), no. 4, 1427-1444.

[32] M. Jensen, Some anomalous evidence regarding market efficiency, Journal of Financial Economics 6 (1978), no. 2-3, 95-102.

[33] C. Jones, G. Kaul, and M. Lipson, Information, trading and volatility, Journal of Financial Economics 36 (1994), no. 1, 127-154.

[34] D. B. Keim, Size related anomalies and stock return seasonality, Journal of Financial Economics 12 (1983), no. 1, 13-32.

[35] M. Kendall, The analysis of economic time series, part I: prices, Journal of the Royal Statistical Society 96 (1953), 11-25.

[36] M. J. Kim, C. R. Nelson, and R. Startz, Mean reversion in stock prices? A reappraisal of the empirical evidence, Review of Economic Studies 58 (1991), no. 3, 515-528, Special issue: the econometrics of financial markets.

[37] C. I. Lee and I. Mathur, Efficiency tests in the Spanish futures markets, Journal of Futures Markets 19 (1999), no. 1, 59-77.

[38] C. Y. Liu and J. He, A variance-ratio test of random walks in foreign exchange rates, Journal of Finance 46 (1991), no. 2, 773-785.

[39] A. W. Lo and A. C. MacKinlay, Stock market prices do not follow random walks: evidence from a simple specification test, Review of Financial Studies 1 (1988), no. 1, 41-66.

[40] A. C. MacKinlay and K. Ramaswamy, Index futures arbitrage and the behavior of stock index futures prices, Review of Financial Studies 1 (1988), no. 2, 137-158.

[41] R. Merton, On estimating the expected return on the market: an exploratory investigation, Journal of Financial Economics 8 (1980), no. 4, 323-361.

[42] K. Ojah and D. Karemera, Random walks and market efficiency tests of Latin American emerging equity markets: a revisit, Financial Review 34 (1999), no. 2, 57-72.

[43] G. Oldfield and R. Rogalski, A theory of common stock returns over trading and non-trading periods, Journal of Finance 35 (1980), 729-751.

[44] J. M. Poterba and L. H. Summers, Mean reversion in stock prices: evidence and implications, Journal of Financial Economics 22 (1988), no. 1, 27-59.

[45] J. Richmond, A general method for constructing simultaneous confidence intervals, Journal of the American Statistical Association 77 (1982), 455-460.

[46] H. V. Roberts, Stock market 'patterns' and financial analysis: methodological suggestions, Journal of Finance 14 (1959), 1-10.

[47] T. Ronen, Tests and properties of variance ratios in microstructure studies, Journal of Financial and Quantitative Analysis 32 (1997), no. 2, 183-204.

[48] Z. Sidak, Rectangular confidence regions for the means of multivariate normal distributions, Journal of the American Statistical Association 62 (1967), 626-633.

[49] L. H. Summers, Does the stock market rationally reflect fundamental values?, Journal of Finance 41 (1986), no. 3, 591-601. 
[50] J. L. Urrutia, Tests of random walk and market efficiency for Latin American equity markets, Journal of Financial Research 18 (1995), 299-309.

[51] P. Westfall, Robustness and power of tests for a null variance ratio, Biometrika 75 (1988), no. 2, 207-214.

[52] $\mathrm{H}$. Working, A random difference series for use in the analysis of time series, Journal of the American Statistical Association 29 (1934), 11-24.

[53] J. H. Wright, Alternative variance-ratio tests using ranks and signs, Journal of Business \& Economic Statistics 18 (2000), no. 1, 1-9.

Kin Lam: Department of Finance \& Decision Sciences, Hong Kong Baptist University, Hong Kong

E-mail address: lamkin@hkbu.edu.hk

May Chun Mei Wong: Dental Public Health, The University of Hong Kong, Hong Kong E-mail address: mcmwong@hkucc.hku.hk

Wing-Keung Wong: Department of Economics, Faculty of Arts \& Social Sciences, National University of Singapore, 1 Arts Link, Singapore 117570

E-mail address: ecswwk@nus.edu.sg 


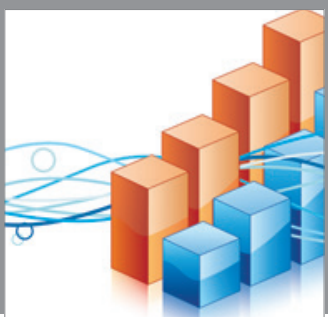

Advances in

Operations Research

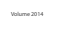

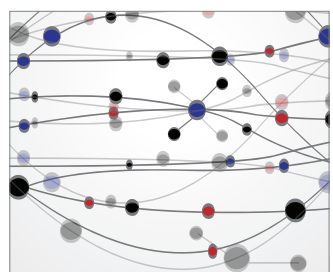

\section{The Scientific} World Journal
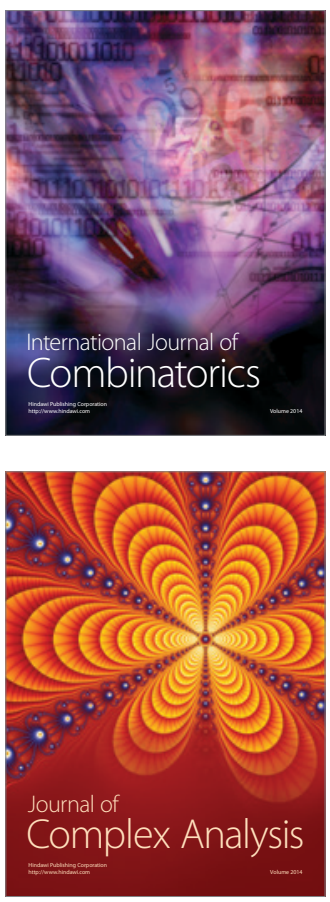

International Journal of

Mathematics and

Mathematical

Sciences
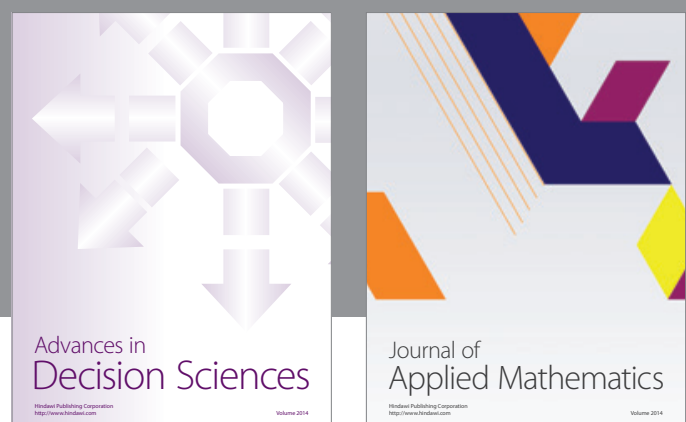

Journal of

Applied Mathematics
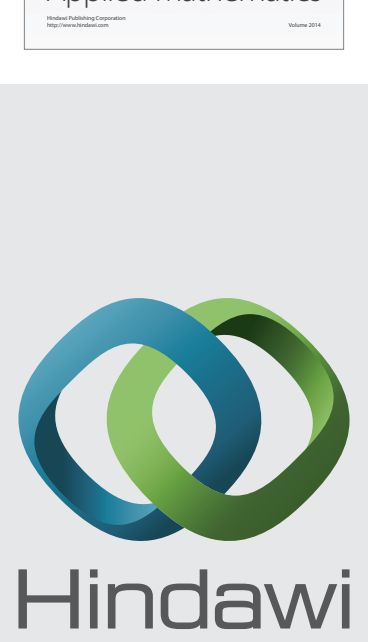

Submit your manuscripts at http://www.hindawi.com
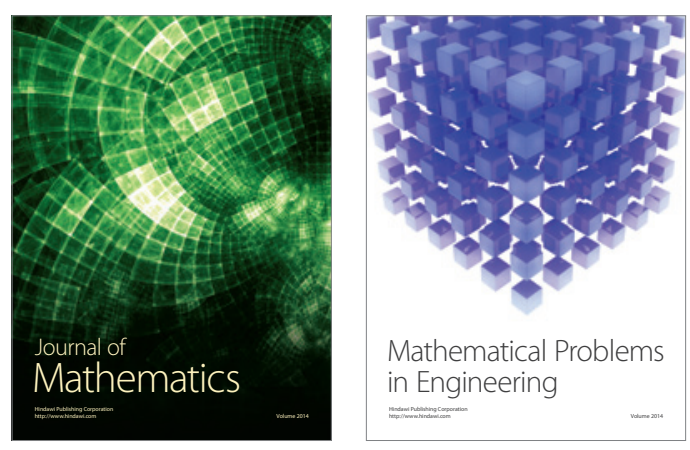

Mathematical Problems in Engineering
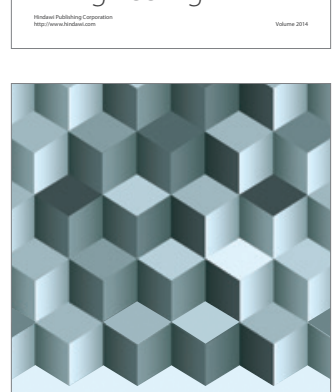

Journal of

Function Spaces
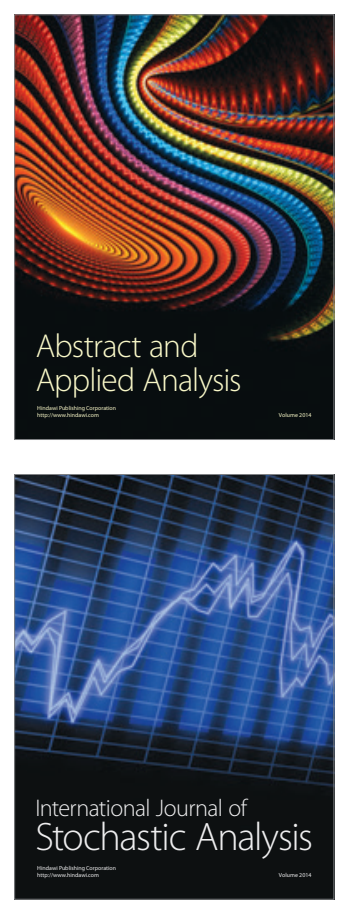

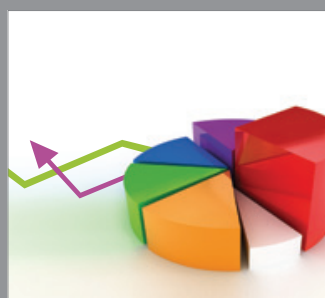

ournal of

Probability and Statistics

Promensencen
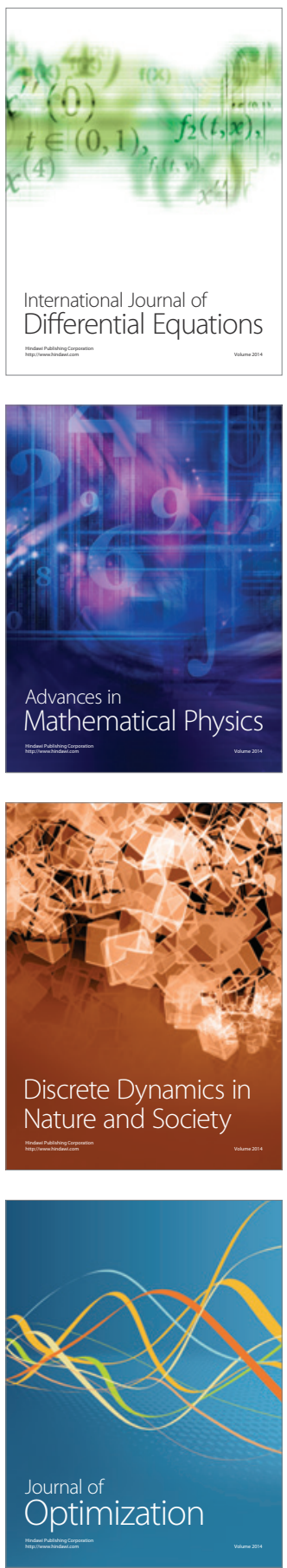